\title{
Conservative Treatment versus Surgical Treatment in the Management of Large Invasive Lobular Carcinoma
}

\author{
HAMADA RASHAD ABDELKADER, M.D.* and MOHAMMED MAMDOUH ASR, M.D.** \\ The Departments of General Surgery* and Surgical Oncology**, Faculty of Medicine, Al-Azhar University
}

\begin{abstract}
Background: The safety of breast conservation therapy (BCT) has not been demonstrated in large ILC tumors, potentially contributing to the higher mastectomy rates seen in ILC.

Aim of Study: The aim of our study was to identify patients with of breast ILC measuring $4 \mathrm{~cm}$ and evaluated difference in recurrence free survival (RFS) between those treated with $\mathrm{BCT}$ versus mastectomy.

Patients and Methods: This is a retrospective study of patients treated for ILC, 60 consecutive treated women with unilateral Stage I or II invasive lobular breast carcinoma were treated with axillary dissection and either mastectomy or conservative breast therapy $(n=30)$ or $B C S(n=30)$, they were admitted to Surgical Oncology Department and General Surgery Department Sayed Galal University Hospital, AlAzhar University.

Results: Disease free survival after 5 -years was $81.3 \%$ in BCT group and $87.2 \%$ in mastectomy group, and after 10 years was $81.3 \%$ in group BCT and $72.1 \%$ in mastectomy group.

Conclusion: For patients with large size ILC, BCT provides similar tumor control as mastectomy, provided that negative margins are achieved. Our findings can be used to help patients and providers make informed choices about surgical options for ILC, which currently has a higher rate of mastectomy than that of IDC.
\end{abstract}

Key Words: Invasive lobular carcinoma - Large tumors Recurrence-free survival - Breast conservation surgery-Mastectomy.

\section{Introduction}

WORLDWIDE breast cancer is the most common invasive cancer in women. In 2012, it comprised $25.2 \%$ of cancers diagnosed in women [1].

Invasive lobular carcinoma (ILC) is the second most common type of breast cancer, constituting $5-15 \%$ of all histologic types of breast cancer. Due to its specific clinical, biologic, and prognostic features, ILC often is considered to be a distinct

Correspondence to: Dr. Hamada Rashad Abdelkader, The Department of General Surgery, Faculty of Medicine, Al-Azhar University clinical entity different from invasive ductal carcinoma (IDC). Patients with ILC present with significantly larger tumors at the time of diagnosis and more often show multifocal or multicentric disease [2].

The diffuse infiltrative growth pattern of ILC poses a difficulty in determining the extent of the tumor. As a result of these characteristics, higher rates of positive surgical resection margins are observed in the primary surgical procedure in ILC compared with IDC. This results in higher rates of re-resection and completion mastectomy for patients with lobular histology [3].

Breast conserving surgery (BCS) sustained marked increases in use in the early 1990s, particularly in the treatment of invasive ductal carcinoma (IDC). Apprehension toward BCS with invasive lobular carcinoma (ILC) was slower to abate, however, and understandably so. Its tendency toward diffuse growth and multifocality, the difficulty in assessing the true extent of tumor on mammography, or the higher reported re-excision rates may give surgeons pause [4].

Over the years, surgery for breast cancer has become less invasive in both the breast and axilla. Surgical techniques have advanced to provide better cosmesis in breast conservation and also in breast reconstruction for woman who require mastectomy. Because definitive treatment of breast malignancy continues to be surgical, the surgeon remains a crucial member of the multidisciplinary team caring for breast cancer patients. Women faced with this diagnosis often have options on how best to manage the breast and axilla in both invasive and in situ malignancy. Decision making surrounds the extent of mastectomy for immediate breast reconstruction, the use of neo-adjuvant therapy, and breast cancer at extremes of age. These can be challenging decisions and often require multidisciplinary care to guide best treatment [5] 
Prospective randomized clinical trials have established the safety of breast conservation therapy (BCT) with lumpectomy followed by radiation for early-stage breast cancers. Most of these pivotal trials included patients with tumors up to $4-5 \mathrm{~cm}$ in size, thereby excluding patients with stage $\mathrm{T} 3$ primary cancers. However, as oncoplastic techniques have improved, the ability to offer BCT to patients with large tumors has increased. Retrospective analyses of BCT in large tumors suggest no difference in overall and disease-specific survival when compared to patients undergoing mastectomy. However, this has not been studied in invasive lobular carcinoma (ILC), the second most common type of breast cancer [6] .

The safety of breast conservation therapy (BCT) has not been demonstrated in large ILC tumors, potentially contributing to the higher mastectomy rates seen in ILC.

The aim of our study was to identify patients with ILC measuring $4 \mathrm{~cm}$ or more and evaluated difference in recurrence free survival (RFS) between those treated with BCT versus mastectomy.

\section{Patients and Methods}

This was a cross-sectional analysis in a cohort of women treated for ILC, 60 consecutive women were treated with unilateral Stage I or II invasive lobular breast carcinoma were treated with axillary dissection and either mastectomy $(\mathrm{n}=30)$ or BCS $(n=30)$ at $)$. Admitted to the Surgical Oncology Department and General Surgery Department Sayed Galal University Hospital, Al-Azhar University, between January 2015 and December 2017 (Surgical Oncology Department and General Surgery Department, Sayed Galal University Hospital). Operative decisions regarding breast conservation or mastectomy were based on patient request, but in the thirty mastectomy was often recommended as the surgical treatment of choice.

We excluded patients who had small tumors (less than $4 \mathrm{~cm}$ ), de novo stage 4 diseases, fewer than six months of follow-up, or missing data about radiation therapy or tumor size. BCT was defined as lumpectomy with or without local tissue rearrangement or oncoplastic reduction mammoplasty. Local tissue rearrangement and shave margins were used at the discretion of the operating surgeon and patient. All patients undergoing $\mathrm{BCT}$ received adjuvant radiotherapy. In BCS patients, routine attempts were made to obtain clear surgical margins. Surgery consisted of total resection of the primary tumor with a $1 \mathrm{~cm}$ rim of normal tissue. Resection edges were subjected to frozen section and, when the margin was positive wider excision was done. Pathological classification (microscopic tumor size, $\mathrm{pT}$ and $\mathrm{pN}$ ) was done according to the UICC-AJCC TNM System.

Details of adjuvant treatment policy and technique have been described previously [7]. The clinical-pathological and treatment characteristics of the patient population were evaluated. Mastectomy patients had generally larger primary.

Patients were seen in follow-up at 3- to 6-month intervals until the end of the 5 th year, and annually thereafter. Chest X-rays, mammograms, bone scans, abdominal ultrasound examinations and blood tests were performed at least yearly. The local-regional recurrences were scored on all patients, including those who also relapsed at distant sites. Malignancy of local-regional recurrence and new primary tumor was proved by histologic or cytologic examination in every case. Distant metastases were defined as a recurrence outside the target volume. Thus, a supraclavicular recurrence was recorded as a regional - not distant - treatment failure. Survival times were calculated as the time from surgery to the date of the event or the end of the follow-up period. Patients lost to follow-up were inserted in the analysis as censored data.

\section{Outcomes:}

Our primary outcomes were 5- and 10-year RFS estimates, defined as the absence of locoregional or distant recurrence at date of last followup. Our secondary endpoint was time to locoregional recurrence and final positive margin rate.

The following end points were studied: Any death for overall survival; death from breast cancer for breast cancer-specific survival; chest wall or ipsilateral in-breast recurrence for local recurrencefree survival; local or regional recurrence, whichever came first, for locoregional recurrence-free survival; distant metastasis for distant disease-free survival.

\section{Statistical analysis:}

Data were analyzed, using the chi-squared test for categorical variables, analysis of variance for continuous variables, and Kaplan-Meier survival estimates. A multivariate logistic regression model was used that included a time-varying regression coefficient to account for non-proportional hazards. Size of tumor was treated as a continuous variable in $1-\mathrm{cm}$ increments.

The sample size was predetermined based on the total number of cases with available data in the study period. Based on this sample size, power 
was $66 \%$ to detect a $40 \%$ increase in hazard ratio for RFS in the BCT group compared to the mastectomy group, using a one-sided alpha of 0.1 , and $77 \%$ to detect a $50 \%$ increase. For positive margin rates, the power was $79 \%$ to detect a $20 \%$ increase in positive margin rates in the BCT group compared to the mastectomy group, using a onesided alpha of 0.05 . Results are reported as hazard ratios (HR) with $95 \%$ confidence intervals $(\mathrm{CI})$.

\section{Results}

Table (1): Demographic and clinical characteristics of studied cases.

\begin{tabular}{|c|c|c|c|c|}
\hline & $\begin{array}{c}\text { Conservative } \\
\text { (30) }\end{array}$ & $\begin{array}{l}\text { Surgical } \\
\text { (30) }\end{array}$ & Test & $p$ \\
\hline $\begin{array}{l}\text { Age (years): } \\
\quad \text { Mean } \pm \mathrm{SD}\end{array}$ & $60.71 \pm 13.5$ & $52.57 \pm 12.7$ & 2.41 & $.019 *$ \\
\hline $\begin{array}{l}B M I\left(\mathrm{~kg} / \mathrm{m}^{2}\right): \\
\quad \text { Mean } \pm \text { SD }\end{array}$ & $28.31 \pm 4.75$ & $27.52 \pm 5.69$ & .584 & .562 \\
\hline $\begin{array}{l}\text { Tumor size }(\mathrm{cm}): \\
\text { Mean } \pm \text { SD } \\
\text { Median (Range) }\end{array}$ & $\begin{array}{l}7.65 \pm 2.03 \\
7.75(4-12.5)\end{array}$ & $\begin{array}{l}9.49 \pm 3.27 \\
9.8(4.3-16.2)\end{array}$ & 2.62 & $.011 *$ \\
\hline $\begin{array}{l}\text { Tumor grade: } \\
\qquad \begin{array}{l}1 \\
2 \\
3\end{array}\end{array}$ & $\begin{array}{l}8(26.7 \%) \\
19(63.3 \%) \\
3(10 \%)\end{array}$ & $\begin{array}{l}7(23.3 \%) \\
20(66.7 \%) \\
3(10 \%)\end{array}$ & .092 & .955 \\
\hline $\begin{array}{c}N \text { stage: } \\
\quad 0 \\
1 \\
2 \\
3\end{array}$ & $\begin{array}{l}13(43.3 \%) \\
10(33.3 \%) \\
4(13.3 \%) \\
3(10 \%)\end{array}$ & $\begin{array}{l}14(46.7 \%) \\
11(36.7 \%) \\
2(6.7 \%) \\
3(13.3 \%)\end{array}$ & .751 & .861 \\
\hline Neoadjuvant Therapy & $10(33.3 \%)$ & $15(50 \%)$ & 1.71 & .191 \\
\hline $\begin{array}{l}\text { Lympho-vascular } \\
\text { Invasion }\end{array}$ & $8(26.7 \%)$ & $4(13.3 \%)$ & 1.67 & .197 \\
\hline Positive margins & $3(10 \%)$ & $4(13.3 \%)$ & .162 & .688 \\
\hline Postoperative seroma & $3(10 \%)$ & $3(10 \%)$ & & 1 \\
\hline Surgical site infection & $4(13.3 \%)$ & $2(6.7 \%)$ & .741 & .389 \\
\hline Postoperative hematoma & $1(3.3 \%)$ & $2(6.7 \%)$ & .351 & .554 \\
\hline
\end{tabular}

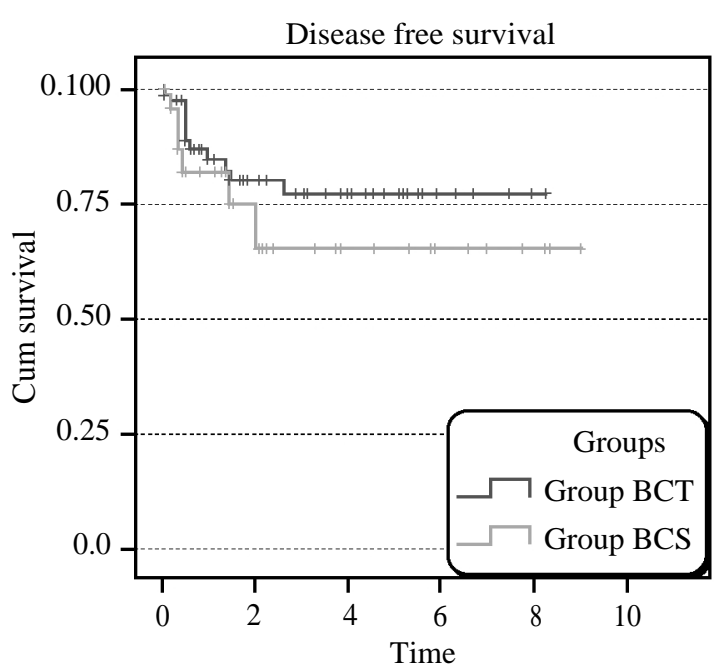

\begin{tabular}{lllll}
\hline Surgical site infection & $4(13.3 \%)$ & $2(6.7 \%)$ & .741 & .389 \\
Postoperative hematoma & $1(3.3 \%)$ & $2(6.7 \%)$ & .351 & .554 \\
\hline
\end{tabular}

Fig. (1): Kaplan Meier survival curve depicting recurrencefree survival in ILC patients.
Disease free survival after 5-years was $81.3 \%$ in BCT group and $87.2 \%$ in BCS group, and after 10 -years was $81.3 \%$ in group BCT and $72.1 \%$ in BCS group.

Table (2): Recurrence-Free Survival (RFS).

\begin{tabular}{llllllll}
\hline & \multirow{2}{*}{ Mean } & SE & \multicolumn{2}{c}{$95 \%$ CI } & \multirow{2}{c}{ Log } & \multicolumn{2}{c}{ Survival at } \\
\cline { 4 - 6 } \cline { 6 - 7 } & & & Lower & Upper & Rank test & 5-years & 10-years \\
\hline BCT & 8.902 & 3.132 & 7.599 & 10.619 & 0.961 & $81.3 \%$ & $81.3 \%$ \\
BCS & 3.724 & 1.145 & 2.833 & 4.615 & & $87.2 \%$ & $72.1 \%$ \\
\hline
\end{tabular}

Table (3): Multivariate logistic regression analysis.

\begin{tabular}{lclc}
\hline & Hazard Ratio & Sig. & $95 \%$ CI \\
\hline Age & 1.145 & .257 & $.906-1.448$ \\
Tumor size & 1.745 & $.024^{*}$ & $1.021-1.962$ \\
Stage 1 & 2.413 & $.011 *$ & $.649=3.646$ \\
Stage 2 & 2.694 & $.013^{*}$ & $.495-3.642$ \\
Stage 3 & 1.110 & $.006^{*}$ & $.816-1.264$ \\
Grade 1 & .465 & .547 & $.039-5.192$ \\
Grade 2 & 1.215 & .273 & $.139-2.679$ \\
Grade 3 & .573 & .456 & $.046-7.167$ \\
Positive margins & 2.307 & $.023 *$ & $1.226=3.112$ \\
Lympho-vascular Invasion & .919 & .106 & $.394-1.267$ \\
\hline
\end{tabular}

Larger tumor size, independent stage and positive margins were significantly associated with shorter RFS.

\section{Discussion}

The current 'gold standard' for treatment of early breast cancer is breast conserving surgery (BCS). The term BCS encompasses different surgical approaches, which differ in the amount of breast tissue removed around the tumor. Lumpectomy describes the excision of the gross tumor mass only, whereas segmentectomy or quadrantectomy involves the removal of tissue surrounding the breast tumor en bloc with overlying skin and underlying fascia [8].

Compared to mastectomy, removal of the tumor with negative surgical margins followed by whole breast radiation therapy leads to equivalent local control but significant better cosmetic results and patient satisfaction. However, given the clinicopathological characteristics of ILC including larger tumor at diagnosis and increased rates of multifocality or multicentricity the effectiveness of breast conserving surgery has been questioned [9]

Prospective randomized clinical trialshave established the safety of breast conservation therapy (BCT) with lumpectomy followed by radiation for early-stage breast cancers. Most of these pivotal 
trials included patients with tumors up to $4-5 \mathrm{~cm}$ in size, thereby excluding patients with stage $\mathrm{T} 3$ primary cancers. However, as oncoplastic techniques have improved, the ability to offer BCT to patients with large tumors has increased $[10,11]$.

Retrospective analyses of BCT in large tumors suggest no difference in overall and disease-specific survival when compared to patients undergoing mastectomy. However, this has not been studied in invasive lobular carcinoma (ILC), the second most common type of breast cancer [12] .

In this study, we aimed to identify patients with ILC measuring $4 \mathrm{~cm}$ and evaluated difference in recurrence free survival (RFS) between those treated with BCT versus mastectomy.

This was a cross-sectional analysis in a cohort of women treated for ILC, 60 consecutive treated women with unilateral Stage I or II invasive lobular breast carcinoma were treated with axillary dissection and either mastectomy $(n=30)$ or BCS $(n=30)$, age in conservative group was $60.71 \pm 13.5$, and was $52.57 \pm 12.7$ in surgical group, mean of BMI was 28.31 \pm 4.75 in BCS and was 27.52 \pm 5.69 in surgical group, Mean \pm SD of tumor size was $7.65 \pm 2.03$ in BCT, and was in $9.49 \pm 3.27,33.3 \%$ of BCT had neoadjuvant Therapy, and $50 \%$ in surgical group had neoadjuvant Therapy, and there was statistical differences between two groups as regard age and tumor size.

Truin et al., 2016 reported that median age of women in ILC was 52.0 (47.0-60.0), and in IDC was 49.0 (43.0-58.0), of the 6401 patients with ILC, $466(7.3 \%)$ received NAC versus $3622(8.1 \%)$ of the 44,597 patients with IDC ( $p=0.02)$. At diagnosis, the patients with ILC were older (median age 52 years) than the patients with IDC (median age 49 years $)(p<0.0001)$ [2]

In agreement with our findings, Abel et al., [6] reported that age in conservative group was 60.71 \pm 13.5 , and was $52.57 \pm 12.7$ in surgical group, mean of BMI was $28.31 \pm 4.75$ in BCS and was $27.52 \pm$ 5.69 in surgical group, mean \pm SD of tumor size was $7.65 \pm 2.03$ in BCT, and was in 9.49 \pm 3.27 , $33.3 \%$ of BCT had neoadjuvant therapy, and $50 \%$ in surgical group had neoadjuvant Therapy, and there were statistical differences between two groups as regard age and tumor size.

In another study of Douma et al., according to the patient's age and chronic diseases at time of presentation, (estimated median age was $50.52 \pm$ 6.22 years for IDC and $51.48 \pm 4.04$ for ILC) There is no significant difference between the studied groups. While there is significant deference between the two groups as regard BMI, the patients of ILC are more likely to be over weigh and obese than IDC patients [1].

The safety of BCT for women with small tumors has been well established in the scientific literature. A randomized controlled trial of Mazor et al., have shown that for patients with stage I or II breast cancers $4 \mathrm{~cm}$ in size, there is no difference in disease free survival or overall survival between BCT and mastectomy cohorts. For tumors greater than $4 \mathrm{~cm}$ in size, however, data are more limited. This is a particularly important question for patients with large ILC tumors, as the unique growth pattern seen in ILC makes complete surgical excision more difficult, and positive margin rates are often higher for patients with ILC compared to those with IDC $[3,12]$.

In the current study, Disease free survival after 5 -years was $81.3 \%$ in BCT group and $87.2 \%$ in BCS group, and after 10 -years was $81.3 \%$ in group $\mathrm{BCT}$ and $72.1 \%$ in BCS group.

In agreement with our findings, Abel et al., reported unadjusted analysis showed no significant difference in RFS estimates at 5 and 10 years among the groups who underwent BCT, mastectomy alone, or mastectomy with radiation. Specifically, the RFS at 5 and 10 years was $80.6 \%$ and $80.6 \%$ for those who underwent BCT, $86.2 \%$ and $71.8 \%$ for those who underwent mastectomy alone, and $78.5 \%$ and $66.8 \%$ for those who underwent mastectomy with radiation ( $p^{1 / 4} 0.45$ and $p^{1 / 4}$ 0.15 , respectively). Without taking follow-up time into account, there were a total of 30 local or regional recurrence events in the mastectomy cohort (20.0\%) and 3 recurrence events in the BCT cohort (10.0\%) [6].

In the present study, we found that larger tumor size, independent stage and positive margins were significantly associated with shorter RFS.

Our results are supported by the study of Abel et al., 2021 which reported that multivariate model that adjusted for age, size of tumor, tumor receptor subtype, grade, N-stage, lymphovascular invasion, and positive margin status showed no benefit of mastectomy without radiation or mastectomy with radiation compared to $\mathrm{BCT}$ on RFS, Larger tumor size was significantly associated with shorter RFS, independent of type of surgical treatment, other factors that were predictive of RFS in the multivariate model included positive margin status, increasing $\mathrm{N}$-stage, and tumor receptor subtype; they also performed a multivariate analysis to 
evaluate the relationship between type of operation and locoregional recurrence as a secondary endpoint, After adjusting for age, tumor size, $\mathrm{N}$-stage, lymphovascular invasion, and positive margins, we found no association between type of operation and time to locoregional recurrence [6]

Another study of Anwar et al., reported that the survival analysis included breast cancer as well as other causes of mortality (all-cause mortalities). The overall survival was 99.3 months $(78.2 \%)$. There was no significant difference in the overall survival between group I and group II patients (94.9 vs. 101.3 months respectively, $p=0.47$ ). Local recurrence did not affect the overall survival $(p=0.1)$ [13].

The previous report on invasive lobular carcinoma was reported by Pestalozzi and colleagues, reported thatthey compared 767 patients with invasive lobular carcinoma to 8607 patients with invasive ductal carcinoma treated in different clinical trials between 1978 and 2002, They found that invasive lobular carcinoma patients were older, had larger but better differentiated estrogen receptor positive tumors, which required mastectomy more often than invasive ductal carcinoma patients. The most important finding in their study was that the disease free and overall survival has changed when the follow-up period was extended. Although the disease free and overall survival were better for invasive lobular carcinoma than ductal carcinoma in the first 6-10 years, they became worse for lobular carcinoma during the latter years of followup. However, the authors did not study the difference in local recurrence rates between patients who had mastectomy and those who had breast conservation for invasive lobular carcinoma [14]

It is important to define specific management strategies for patients with invasive lobular carcinoma. We recommend and encourage colleagues in specialized breast units to study and report their results after prolonged follow-up periods. Recent evidence suggests that survival outcome could be different if it is studied with a longer periods of follow-up.

In conclusion, for patients with large size ILC, BCT provides similar tumor control as mastectomy, provided that negative margins are achieved, our findings can be used to help patients and providers make informed choices about surgical options for ILC, which currently has a higher rate of mastectomy than that of IDC. Increased representation of ILC patients in clinical trials is needed to improve outcomes and tailor care to patients with this unique tumor type.

\section{References}

1- DOUMA A.M.E., HOSNY BENDARY S., YOSRY ELAGAMAWI A., MAHMOUD ZAYED A. and MOHAMED ABD EL-HAMID N.: Assessment Of Surgical Management Of Female Breast Cancer Patients After Neoadjuvant Systemic Therapy For Invasive Ductal Versus Invasive Lobular Carcinoma (T3 Stage). Al-Azhar Medical Journal, 49 (4): 1519-1527. Doi: 10.12816/Amj.2020. 120555, 2020.

2- TRUIN W., VUGTS G., ROUMEN R.M., MAASKANTBRAAT A. J., NIEUWENHUIJZEN G.A., VAN DER HEIDEN-VAN DER LOO M., TJAN-HEIJNEN V.C. and VOOGD A.C.: Differences in Response and Surgical Management with Neoadjuvant Chemotherapy in Invasive Lobular Versus Ductal Breast Cancer. Annals of Surgical Oncology, 23 (1): 51-57. https://doi.org/10.1245/s10434015-4603-3, 2016.

3- FORTUNATO L., MASCARO A., POCCIA I., et al.: Lobular breast cancer: Same survival and local control compared with ductal cancer, but should both be treated the same way? Analysis of an institutional database over a 10-year period. Ann. Surg. Oncol., 19: 1107e1114. https://doi.org/10.1245/s10434-011-1907-9, 2012.

4- SHARMA S.: Surgical management of lobular carcinoma from a national screening program: A retrospective analysis. Eur. J. Surg. Oncol., 41 (1): 79e85, 2015.

5- De LORENZI F., LOSCHI P., BAGNARDI V., et al.: Oncoplastic breast-conserving surgery for tumors larger than 2 centimeters: Is it oncologically safe? A matchedcohort analysis. Ann. Surg. Oncol., 23: 1852-1859, 2016.

6- ABEL M.K., CASE E. BRABHAM, RUBY GUO, KELLY FAHRNER-SCOTT, JASMINE WONG, MICHAEL ALVARADO, CHERYL EWING, LAURA J. ESSERMAN and RITA A. MUKHTAR: Breast conservation therapy versus mastectomy in the surgical management of invasive lobular carcinoma measuring $4 \mathrm{~cm}$ or greater; The American Journal of Surgery, 221: 32e36, 2021.

7- FODOR, J. TÓTH, T. MAJOR, et al.: Incidence and time of occurrence of regional recurrence in stage I-II breast cancer: Value of adjuvant irradiation, Int. J. Radiat Oncol. Biol. Phys., 44: pp. 281-287, 1999.

8- KONSTANTIN D. and DANIEL F.: Clinical Presentation and Surgical Management of Invasive Lobular Carcinoma of the Breast. Breast disease, 30. 31-7. 10.3233/BD-2009$0277,2009$.

9- ABDEL-FATAH, POWE D.G., HODI Z., REIS-FILHO J.S., LEE A.H. and ELLIS I.O.: Morphologic and molecular evolutionary pathways of low nuclear grade invasive breast cancers and their putative precursor lesions: Further evidence to support the concept of low nuclear grade breast neoplasia family, Am. J. Surg. Pathol., 32: 513523,2008

10- FISHER B., JEONG J.H., ANDERSON S., BRYANT J., FISHER E.R. and WOLMARK N.: Twenty-fiveyear follow-up of a randomized trial comparing radical mastectomy, total mastectomy, and total mastectomy followed by irradiation. N. Engl. J. Med., 347 (8): 567e575. https://doi.org/10.1056/NEJMoa020128, 2002.

11- FITZAL F., RIEDL O., WUTZL L., et al.: Breastconserving Surgery for T3/T4 Breast Cancer: An Analysis 
of 196 Patients. Breast Cancer Res Treat, https://doi.org/ 10.1007/s10549-006-9325-6, 2007.

12-MAZOR A.M., MATEO A.M., DEMORA L., et al.: Breast conservation versus mastectomy in patients with T3 breast cancers $(>5 \mathrm{~cm})$ : An analysis of 37,268 patients from the National Cancer Database. Breast Canc Res Treat. https://doi.org/ 10.1007/s10549-018-5007-4, 2019.

13- ANWAR I.F., DOWN S. RIZVI, FAROOQ N., BURGER A., MORGAN A. and HUSSIEN M.I.: Invasive lobular carcinoma of the breast: Should this be regarded as a chronic disease?, International Journal of Surgery, Volume 8, Issue 5, Pages 346-352, 2010.

14- PESTLOZZI, ZAHRIEH D., ALLON E., GUSTERSON B.A., PRICE K.N., LINDTNER J., et al.: Distinct Clinical and prognostic features of infiltrating lobular carcinoma of the breast: Combined results of 15 International Breast Cancer Study Group Clinical Trials, J. Clinic Oncol., 26 (18): pp. 3006-3014, 2008.

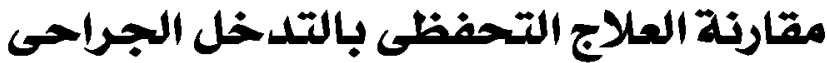

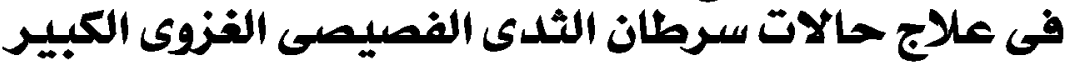

$$
\begin{aligned}
& \text { لم يتم إثبات سلامة العلاج التحفظى للثىى فى حالات أودام الثىى الخبيثة من النوع الفصيصى الفائر الكبير والتى غالب العلاج فيها حتى }
\end{aligned}
$$

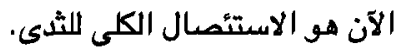

الهدف من الدراسة: مقارنة رجوع الورم ما بين الحالات التى تمت معالجتها بالاستئمال الكلى للثى والعلاج التحفظى للثىى.

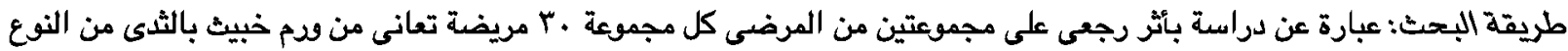

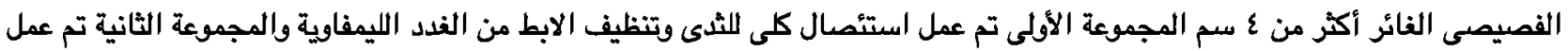

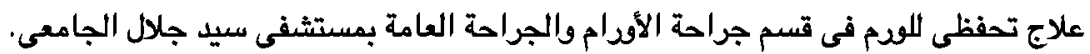
تتيجية البحث: وجد أن فترات المتابعة والخالية من وجود ارتجاع للومث فى المجموعتين تكاد تكون متقاربة وذلك خلال فترات متابعة خمس وعشر سنين.

الملخص: حالات أودام الثدى الضبيثة من النوع الفصيصى ذات الحجم الكبير أكبر من ع سم يمكن علاجها بالطريق التحفظية من دون

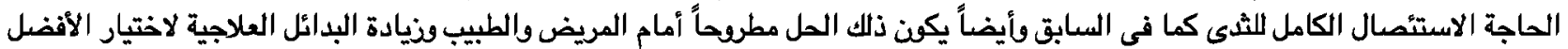

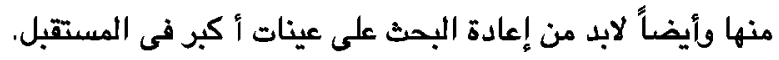

